\section{Chromosomal abnormalities and psychosis}

\author{
WALTER J. MUIR, BENJAMIN S. PICKARD and DOUGLAS H. R. BLACKWOOD
}

\begin{abstract}
Summary The search for susceptibility genes for schizophrenia and severe affective disorder has been enhanced by the study of cy togenetic abnormalities that disrupt genes directly. One such gene is $\mathrm{DISCl}$ and there is increasing evidence that it may be an important modulator of risk of psychosis.
\end{abstract}

\section{Declaration of Interest None. \\ Funding detailed in Acknowledgements.}

The chromosome count of the human species was correctly ascertained 50 years ago and there followed an explosion of interest in chromosome abnormalities and their medical associations. Abnormalities which were visible by light microscopy of suitably stained chromosome preparations were found in relatively common syndromes. Most notable were trisomies of entire chromosomes, such as chromosome 21 in Down's syndrome and the various sex chromosome aneuploidies, or major deletions of parts of chromosomes such as the short arm of chromosome 5 in cri-du-chat syndrome. There were important technological developments in the late 1960s. New methods for staining chromosomes in metaphase produced banding patterns that could be used to clearly distinguish individual chromosomes and reliably map the position of internal chromosomal rearrangements. Altered cell culture conditions revealed a new form of abnormality, an X-chromosome fragile site in men causing moderate cognitive impairment and a set of variable physical features including macro-orchidism. This cytogenetic marker was a pointer to the later discovery of a large DNA repeat sequence that was methylated by cells, silencing the expression of an underlying gene and leading to the cognitive and behavioural outcomes of the fragile-X syndrome, the most common inherited cause of learning disability. These discoveries stimulated research into the underlying neurobiology of fragile-X syndrome. Sometimes abnormalities are restricted to specific tissues. The 'Philadelphia chromosome' is a reciprocal translocation involving chromosomes 9 and 22 in malignant cells from chronic myeloid leukaemia. Here two genes have been broken and the resulting fusion gene produces a chimeric and pathological protein which is the target for drug therapy. Such 'acquired' chromosomal rearrangements, occurring only in affected cells, have been crucial to understanding haematological malignancies but also provide a paradigm applicable to constitutional genetic disorders, including those of psychiatry.

\section{CYTOGENETIC ABNORMALITIES AND THE GENETICS OF SCHIZOPHRENIA}

Schizophrenia remains an enigma but genetic components undoubtedly influence its development, with clear evidence available from twin, family and adoption studies. The advent of DNA-based chromosomal markers facilitated the search for susceptibility genes, initially by linkage within multiply affected families. Cytogenetics played a role from the start and an early linkage study on chromosome 5 was stimulated by the discovery of a chromosome rearrangement in a Canadian family with schizophrenia. However, most early linkage studies produced conflicting findings, perhaps as a result of locus and allelic heterogeneity. Recently, several susceptibility genes have been proposed for schizophrenia - neuregulin (NRG1) and dysbindin (DTNBP1) have considerable support but do not account for all the genetic risk. Other genes must contribute and crucial clues have been provided by cytogenetic studies.
An important group of patients are those with learning disability and schizophrenia, an association which was originally described by Kraepelin. The risk of schizophrenia is three times higher in people with mild learning disability than in the general population and chromosomal variants and abnormalities are increased (Doody et al, 1998). Structural magnetic resonance imaging in these individuals reveals abnormalities of the hippocampus and amygdala that are more severe than in people with schizophrenia alone and very different from people with learning disability alone. Chromosomal abnormalities in patients with comorbidity may shed light on schizophrenia in general. Velocardiofacial and DiGeorge syndromes are associated with learning disability and usually arise from small, relatively frequent ( 1 in 4000 children) deletions on the long arm of chromosome 22 (22q11 deletion syndromes - 22q11DS). The associated phenotype is highly variable with congenital heart defects occurring in approximately three-quarters of patients. Approaching $90 \%$ have a $3-\mathrm{Mbp}$ deletion encompassing 30 genes. This is a true contiguous gene syndrome with the clinical phenotype being a consequence of reduced expression of a set of genes (haploinsufficiency). The relative risk of schizophrenia in people with 22q11DS is around 25-30, and family linkage and candidate gene association studies in non-deletion schizophrenia independently point to a locus on $22 \mathrm{q} 11$ (Owen, 2005).

Two genes in the interval stand out through linkage and association findings as possible candidates for psychiatric outcomes - catechol-O-methyltransferase (COMT; involved in monoamine metabolism) and a mitochondrial enzyme proline dehydrogenase (PRODH). A common polymorphism in COMT alters the enzyme's structure and function. Several groups have shown that COMT genotypes are related to prefrontal executive function, and a longitudinal study identified the low activity allele as a key variable in determining prefrontal cortical volume decline and the subsequent development of schizophrenia (Gothelf et al, 2005). Experiments in mice deficient in Prodh suggest a role for this gene in learning and memory through hippocampal glutamatergic systems (Paterlini et al, 2005). Furthermore, epistatic interactions between Prodh and Comt were observed at the molecular and behavioural levels; for example, Comt inhibition 
Table I Studies of DISCI linkage in schizophrenia or schizoaffective disorder and of DISCI polymorphisms and neuropsychological and neuroimaging phenotypes in schizophrenia and the general population

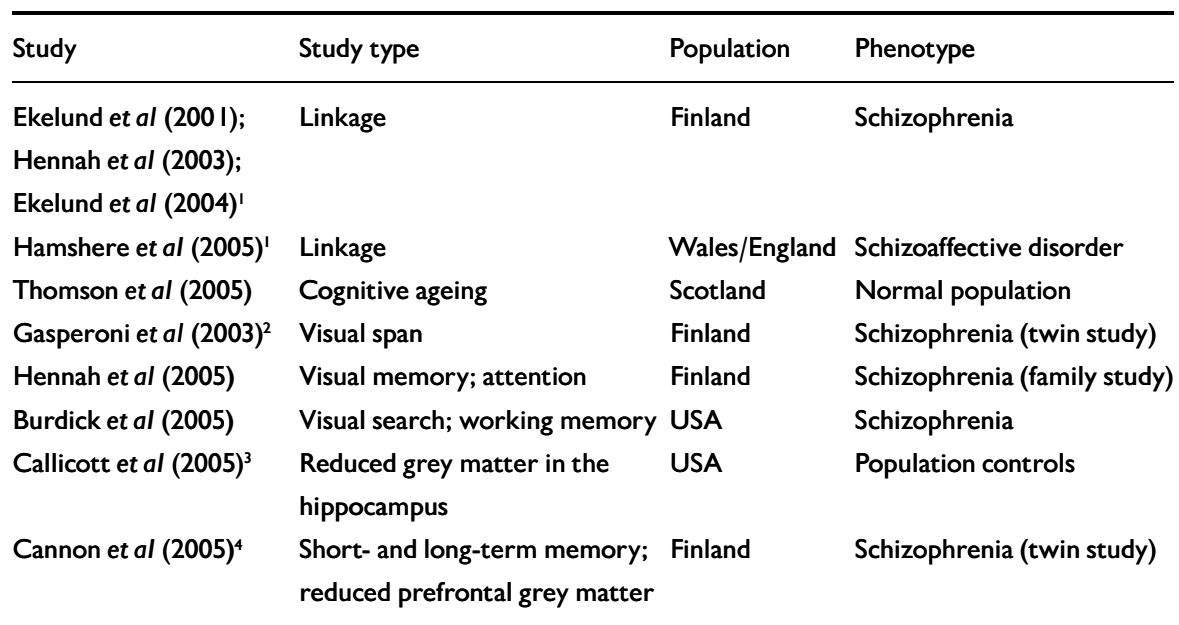

I. Studies were positive for linkage.

2. Association with one marker.

3. Association with a common single nucleotide polymorphism that is also overtransmitted in schizophrenia.

4. Combined imaging and psychology study.

exaggerated the effects of Prodh deficiency on pre-pulse inhibition, a measure thought to be relevant to schizophrenia. This may provide a clue as to how two key neurochemical hypotheses of schizophrenia, dopaminergic and glutamatergic, may be linked at a molecular level in 22q11DS.

\section{DISCI AND SCHIZOPHRENIA}

Deletions usually remove large stretches of a chromosome but reciprocal translocations between chromosomes, in their balanced form, can break within narrow bounds and have been powerful tools in clearly identifying disrupted genes and linking these to clinical phenotypes. Where chromosomal abnormalities are associated with a clinical disorder in several members of the same family or are common to several unrelated patients, a causal link is likely and can be investigated by examining the DNA structure at and around the break (MacIntyre et al, 2003). In the late 1960s extensive population surveys conducted by the Medical Research Council in Edinburgh identified an individual with a reciprocal translocation between chromosomes 1 and $11(+(1 ; 11))$. The segregation of this rearrangement was followed through a greatly extended pedigree. Clinical studies, with the investigators masked to karyotype status, confirmed and extended follow-up reports of schizophrenia, major depression and bipolar disorder in translocation carriers but not in family non-carriers
(Blackwood et al, 2001). Subsequent analysis showed that the chromosome 1 breakpoint directly disrupted two overlapping genes, termed disrupted-in-schizophrenia 1 and 2 (DISC1 and DISC2). DISC2, coded on the opposite DNA strand to DISC1, is transcribed but not translated and is possibly an RNA gene with some regulatory role (Millar et al, 2001). DISC1 encodes a novel brain-expressed protein, is an important modulator of risk for schizophrenia and severe affective disorder in people without cytogenetic abnormalities and may also influence cognition and brain structure in the general population (Table 1). A frameshift DNA mutation in DISC1, which produces reduced amounts of a truncated DISC1 protein, has been described in an American family with schizophrenia and schizoaffective disorder (Sachs et al, 2005).

\section{WHAT DOES DISCI DO?}

DISC1 likely has a role in developing and adult brain in a range of cellular processes, including microtubule and mitochondrial function. Interacting proteins include Nudel (NDEL1), a microtubule-associated protein that helps maintain neuronal morphology. The Nudel/DISC1 complex interacts with the protein LIS1, mutations in which lead to lissencephaly, a disorder of neuronal migration with disorganised cerebral cortex formation. Studies in mice of the DISC1 orthologue show strong hippocampal expression throughout development as well as in the developing cortex. Peaks of expression occur during the maximum period of foetal neurogenesis as well as during puberty in the mouse, and a similar distribution pattern is seen in the adult monkey brain. Such findings are in keeping with our understanding of the neuroanatomy of schizophrenia.

\section{LINKING SCHIZOPHRENIA AND AFFECTIVE DISORDERS}

Findings in the family with $t(1 ; 11)$ support a role for DISC1 in both schizophrenia and affective disorders. Some of the observed phenotype/genotype relationships may be related to where DISC1 localises within neurons, with different subcellular isoform distribution in brains from people with schizophrenia compared with those with major depression (Sawamura et al, 2005).

An important new understanding of the role of DISC1 in schizophrenia has emerged from study of another chromosome abnormality in a patient with severe schizophrenia in whom a reciprocal balanced translocation between chromosomes 1 and 16 directly disrupted the phosphodiesterase-4 type $\mathrm{B}$ gene (PDE4B). In itself this was interesting since the antidepressant rolipram is a direct inhibitor of PDE4 proteins. However, the unexpected finding was that the PDE4B protein forms an intracellular complex with DISC1 that appears to be regulated by cellular cyclic AMP and protein kinase systems (Millar et al, 2005). This suggests that these genes link schizophrenia and mood disorders and that they may identify target proteins for possible therapeutic interventions.

\section{CONCLUSION}

A large body of evidence has accumulated over the past few years to suggest that DISC1 has an important role in the development of psychosis. It is probable that the analysis of other rare chromosome abnormalities using increasingly powerful tools, including comparative genome hybridisation methods, will give further new insights into the pathogenesis of psychosis. We recommend their study as an important adjunct in psychiatric genetics and urge clinicians and researchers to identify new patients with such abnormalities. 


\section{ACKNOWLEDGEMENTS}

In the past 5 years the authors have received support from the Medical Research Council, the Wellcome Trust, the Chief Scientist's Office of the Scottish Executive, the Health Care Trust and joint University/Industry initiatives with Azko-Nobel (Organon) and Merck, Sharp \& Dohme.

\section{REFERENCES}

Blackwood, D. H., Fordyce, A., Walker, M. T., et al (200I) Schizophrenia and affective disorders -

cosegregation with a translocation at chromosome lq42 that directly disrupts brain-expressed genes: clinical and P300 findings in a family. American Journal of Human Genetics, 69, 428-433.

Burdick, K. E., Hodgkinson, C. A., Szeszko, P. R., et al (2005) $\mathrm{DISCl}$ and neurocognitive function in schizophrenia. Neuroreport, 16, 1399-1402.

Callicott, J. H., Straub, R. E., Pezawas, L., et a (2005) Variation in DISCl affects hippocampal structure and function and increases risk for schizophrenia. Proceedings of the National Academy of Sciences of the USA, 102, 8627-8632.

Cannon, T. D., Hennah, W., van Erp, T. G., et al (2005) Association of DISCI/TRAX haplotypes with schizophrenia, reduced prefrontal gray matter, and impaired short- and long-term memory. Archives of General Psychiatry, 62, 1205-1213.

Doody, G. A., Johnstone, E. C., Sanderson, T. L., et al (1998) 'Pfropfschizophrenie' revisited. Schizophrenia in people with mild learning disability. British Journal of Psychiatry, 173, 145-153.

Ekelund, J., Hovatta, I., Parker, A., et al (200I) Chromosome I loci in Finnish schizophrenia families. Human Molecular Genetics, 10, 1611-1617.

Ekelund, J., Hennah, W., Hiekkalinna, T., et al (2004) Replication of 1942 linkage in Finnish schizophrenia pedigrees. Molecular Psychiatry, 9, 1037-1041.

WALTER J. MUIR, FRCPsych, Division of Psychiatry, BENJAMIN S. PICKARD, PhD, Medical Genetics Section, DOUGLAS H. R. BLACKWOOD, PhD, FRCPE, FRCPsych, Division of Psychiatry, School of Molecular and Clinical Medicine, University of Edinburgh, Edinburgh, UK

Correspondence: Dr Walter J. Muir, Division of Psychiatry, University of Edinburgh, KennedyTower, Royal Edinburgh Hospital, Morningside Park, Edinburgh EHIO 5HF, UK. E-mail: walter.muir@ed.ac.uk

(First received 16 January 2006, final revision 26 February 2006, accepted 3 March 2006)

Gasperoni, T. L., Ekelund, J., Huttunen, M., et al (2003) Genetic linkage and association between chromosome 19 and working memory function in schizophrenia. American Journal of Medical Genetics Part B: Neuropsychiatric Genetics, 116, 8-16.

Gothelf, D., Eliez, S., Thompson, T., et al (2005) COMT genotype predicts longitudinal cognitive decline and psychosis in 22ql I.2 deletion syndrome. Nature Neuroscience, 8, 1500-1502.

Hamshere, M. L., Bennett, P., Williams, N., et al (2005) Genomewide linkage scan in schizoaffective disorder: significant evidence for linkage at lq42 close to $\mathrm{DISCl}$, and suggestive evidence at 22qll and $19 \mathrm{pl} 3$. Archives of General Psychiatry, 62, 1081-1088.

Hennah, W., Varilo, T., Kestila, M., et al (2003) Haplotype transmission analysis provides evidence of association for DISCl to schizophrenia and suggests sex-dependent effects. Human Molecular Genetics, I2, 3I5I-3I59.

Hennah, W., Tuulio-Henriksson, A., Paunio, T., et al (2005) A haplotype within the DISCl gene is associated with visual memory functions in families with a high density of schizophrenia. Molecular Psychiatry, 10, 1097 1103.

Maclntyre, D. J., Blackwood, D. H., Porteous, D. J., et al (2003) Chromosomal abnormalities and mental illness. Molecular Psychiatry, 8, 275-287.

Millar, J. K., Christie, S., Anderson, S., et al (200I) Genomic structure and localisation within a linkage hotspot of Disrupted In Schizophrenia I, a gene disrupted by a translocation segregating with schizophrenia. Molecular Psychiatry, 6, 173-178.

Millar, J. K., Pickard, B. S., Mackie, S., et al (2005) $\mathrm{DISCl}$ and PDE4B are interacting genetic factors in schizophrenia that regulate CAMP signaling. Science, $\mathbf{3 1 0}$ ||87-||9|.

Owen, M. J. (2005) Genomic approaches to schizophrenia. Clinical Therapy, 27 (suppl. A), S2-7.

Paterlini, M., Zakharenko, S. S., Lai, W. S., et a (2005) Transcriptional and behavioral interaction between 22qll.2 orthologs modulates schizophreniarelated phenotypes in mice. Nature Neuroscience, 8 I586-1594.

Sachs, N. A., Sawa, A., Holmes, S. E., et al (2005) A frameshift mutation in Disrupted in Schizophrenia I in an American family with schizophrenia and schizoaffective disorder. Molecular Psychiatry, 10, 758-764.

Sawamura, N., Sawamura-Yamamoto, T., Ozeki, Y., et al (2005) A form of DISCl enriched in nucleus: altered subcellular distribution in orbitofrontal cortex in psychosis and substance/alcohol abuse. Proceedings of the National Academy of Sciences of the USA, 102, 1187-1192.

Thomson, P. A., Harris, S. E., Starr, J. M., et al (2005) Association between genotype at an exonic SNP in DISCl and normal cognitive aging. Neuroscience Letters, $389,4 I-45$. 